\title{
Trabalho Colaborativo com Suporte Digital: uma experiência de formação docente
}

\author{
Maria Auricélia da Silva ${ }^{1}$, José Aires de Castro Filho \\ ${ }^{1}$ Unidade Universitária Federal de Educação Infantil Núcleo de Desenvolvimento da \\ Criança - Universidade Federal do Ceará (UFC) - Campus do Pici - Bloco 859 - \\ Fortaleza-CE \\ ${ }^{2}$ Instituto UFC Virtual - Universidade Federal do Ceará (UFC) - Campus do Pici - \\ Bloco $9011^{\circ}$ andar, Fortaleza-CE \\ silvauricelia@gmail.com, aires@virtual.ufc.br
}

\begin{abstract}
This paper describes an elementary school teacher training process of a school awarded the Project "Um Computador por Aluno" (UCA). The research objectives were: probe the elementary school teachers expectations on the provision of training on collaborative network in the UCA Project; promote training on collaborative work with computational support for elementary school teachers; follow the training process and the results of training. The methodology used was participatory research. The results indicated that teacher training led to the acquisition of educational, technical and technological knowledge.
\end{abstract}

Resumo. Este artigo descreve um processo de formação de professores do Ensino Fundamental de uma escola contemplada com o Projeto Um Computador por Aluno (UCA). Os objetivos da pesquisa consistiram em: sondar as expectativas de professores do Ensino Fundamental sobre a oferta de uma formação sobre trabalho colaborativo em rede no Projeto UCA; promover formação acerca do trabalho colaborativo com suporte computacional para professores do Ensino Fundamental; acompanhar o processo formativo e os resultados da formação. A metodologia utilizada foi a pesquisa participante. Os resultados indicaram que a formação docente propiciou a aquisição de conhecimentos didáticos, técnicos e tecnológicos.

\section{Introdução}

A comunicação mediada pelas Tecnologias Digitais de Informação e Comunicação (TDIC) é uma prática contemporânea capaz de favorecer a criação de novas metodologias, oportunizar a realização de experiências que utilizam o suporte de recursos tecnológicos e ferramentas online, muitas das quais colaborativas, para promover ensino e aprendizagem de conteúdos escolares.

Essas formas de comunicação suscitam, portanto, diversas estratégias pedagógicas em diferentes tempos e espaços, na perspectiva colaborativa. Mas será que a escola consegue integrar ao seu fazer cotidiano essas ações que acontecem fora dela? Como mobilizar os recursos digitais para apoiar práticas colaborativas, interdisciplinares, presenciais ou virtuais com as condições reais e efetivas da escola? Como os professores enfrentam esses novos desafios? 
A implantação do Projeto Um Computador por Aluno (UCA), no período de 2010 a 2012, oportunizou o uso intensivo do computador e da Internet nas escolas brasileiras contempladas. O referido Projeto teve como referência a proposta de distribuição de laptops para crianças pela Organização One Laptop per Children (OLPC), organização dirigida por Nicholas Negroponte. A proposta brasileira, contudo, consistiu na inclusão digital dos professores, gestores e alunos de escolas públicas do País a partir da inserção de laptops educacionais em sala de aula.

A oferta de formação para o uso das TDIC a todos os professores e gestores das escolas UCA permitiu o acompanhamento desses profissionais a partir de sua inclusão digital até a utilização do laptop como recurso pedagógico, mediante o planejamento conjunto e a execução de atividades em que os recursos digitais foram utilizados como suporte às práticas pedagógicas. A partir desse Projeto, surgiram novos desafios e possibilidades para ensinar e aprender com o suporte da tecnologia.

Desse modo, os objetivos desta investigação consistiram em: sondar as expectativas de professores do Ensino Fundamental sobre a oferta de uma formação sobre trabalho colaborativo em rede no Projeto UCA; promover formação acerca do trabalho colaborativo com suporte computacional para professores do Ensino Fundamental; acompanhar o processo formativo e os resultados da formação.

Este artigo discute, portanto, a aprendizagem colaborativa com suporte computacional, apresenta a metodologia desenvolvida durante a realização da pesquisa e os resultados obtidos, os quais revelaram boas perspectivas docentes sobre trabalho colaborativo com suporte do laptop.

\section{Aprendizagem Colaborativa com Suporte Computacional}

A Aprendizagem Colaborativa com Suporte Computacional (CSCL) teve origem nas ciências que se ocupam da aprendizagem em grupo, especialmente quando o computador é utilizado como suporte. Como explicam Stahl, Koschman e Suthers (2006), o estudo da aprendizagem em grupos teve início antes dos anos 1960, mesmo quando ainda não existiam os computadores pessoais conectados em rede.

Sobre o surgimento da CSCL, é difícil assegurar quando ela despontou como um campo próprio de estudo ou como um paradigma emergente de ensino com tecnologia. A despeito de o primeiro workshop e a primeira conferência internacional sobre CSCL terem ocorrido em 1990 e em 1995, respectivamente, O'Malley e Scanlon já haviam usado o termo aprendizagem colaborativa apoiada por computador em 1989 [Liponnen, Hakkarainen e Paavola 2004].

Stahl, Koschman e Suthers (2006) afirmam que a ascensão da CSCL ocorreu nos anos 1990, em contraposição aos softwares que propunham a aprendizagem individual e isolada. Tal proposta, naturalmente, envolve uma mudança no conceito de aprendizagem, no fazer cotidiano da escola e nas formas de ensinar e aprender. Há que se considerar a aprendizagem do grupo e a de cada um de seus integrantes, pois ambas não se desvinculam, já que, como bem afirmam esses autores (2006, p. 4), "na CSCL, a aprendizagem é analisada como um processo do grupo, sem desconsiderar a análise da aprendizagem individual".

Desse modo, a CSCL tem como propósito a aprendizagem em grupo, em colaboração com outros estudantes, em lugar de aprender diretamente com o professor, 
numa relação que deixa de ser vertical e passa a ser horizontal, não-linear, heterárquica. Como propõe Lipponen (2002), a CSCL ocupa-se de compreender como a aprendizagem colaborativa apoiada pela tecnologia pode melhorar a interação e o trabalho e como a tecnologia pode favorecer o compartilhamento de conhecimentos e experiências entre os membros de um grupo.

Nesse processo, o docente desempenha um importante papel na oferta de suporte e orientação durante a realização das atividades, na mediação entre o conhecimento e os alunos, no acompanhamento dos caminhos que os estudantes percorrem para a busca de soluções, a construção coletiva do conhecimento e a produção dos resultados. Além disso, existem aspectos como distribuição do tempo, negociação das ideias, tomada de decisões, relações que se estabelecem entre os membros do grupo, que também são mediadas pelo professor, ainda que o faça mediante colaboração com os alunos [Silva, Barbosa e Castro-Filho 2013].

Almeida e Prado (2003, p. 53) reconhecem o papel do professor nesse processo, visto que a mediação docente deve ser "uma ação incitadora do diálogo, da representação do pensamento e do trabalho compartilhado, comprometido e solidário sendo exercitada tanto por ele como pelos demais participantes do ambiente por meio da proposição de estratégias adequadas”.

Abegg, Bastos e Müller (2010) defendem que o trabalho colaborativo em rede mediado pela tecnologia potencializa a formação social, favorece o crescimento do grupo, estimula o trabalho em conjunto e concorre para que os colaboradores desenvolvam uma compreensão mais profunda do conhecimento produzido coletivamente. As plataformas colaborativas, a partir da mediação docente, oportunizam a formação de coautores do conhecimento em lugar de formar, apenas, consumidores de informações produzidas por outrem.

Na concepção de Aparici e Acedo (2010), as tecnologias digitais favorecem a formação de redes de aprendizagem, nas quais se pode realizar um trabalho de colaboração. Contudo, para que o trabalho colaborativo se desenvolva, os autores ressaltam dois pontos imprescindíveis: coautoria coletiva e comunicação horizontal. Nesse sentido, Aparici e Acedo (2010) corroboram o pensamento de Lima (2008) e Abegg, Bastos e Müller (2010) ao enfatizar que a colaboração dos diferentes atores do processo colaborativo caracteriza-se pela coautoria, uma vez que a participação dos integrantes do grupo agrega valor à produção coletiva sem a preponderância de um autor sobre o outro. Todas as produções são discutidas e valorizadas, sem prioridade de autor, tempo ou espaço. A mudança nos papeis do professor e dos alunos constitui o eixo central e o suporte para a coautoria e a produção colaborativa [Castro-Filho, Silva e Maia 2015].

Percebe-se, portanto, a importância da ação docente, da concepção didática e da prática pedagógica desenvolvida para que a colaboração seja vivenciada. Assim, tornase imperioso aliar uma boa estrutura tecnológica a uma postura pedagógica consistente quanto ao trabalho colaborativo para que se obtenha êxito na CSCL.

\section{Percurso metodológico}

A pesquisa participante propõe alternativas de trabalho e elaboração de estratégias com os diversos segmentos populares, a fim de promover processos de produção e divulgação de conhecimentos construídos coletivamente. Le Boterf (1984, p. 52) 
esclarece que "a pesquisa participante vai [...] procurar auxiliar a população envolvida a identificar por si mesma os seus problemas, a realizar a análise crítica destes e a buscar as soluções adequadas".

Assim, a pesquisa participante foi eleita a metodologia desta investigação em razão dos seguintes pontos: a escola esteve comprometida com a pesquisa desde o lançamento da ideia pela pesquisadora, sentiu-se valorizada pela escolha do locus e desejava estudar e implementar novas estratégias de ensino e aprendizagem com suporte computacional; todos os passos da pesquisa foram negociados com os gestores e os professores; a pesquisadora assumiu o compromisso de integrar-se à escola sem negar o fazer pedagógico já praticado cotidianamente; foram adotados o diálogo, a reflexão, a ação e o suporte computacional como elos mediadores em todo o processo de pesquisa.

\subsection{Locus, sujeitos da investigação e coleta de dados}

Esta pesquisa foi desenvolvida em uma escola do interior cearense participante do Projeto UCA, neste trabalho denominada Escola PAS. A adesão foi feita por todos os profissionais diretamente ligados às atividades pedagógicas e administrativas, de modo que 23 profissionais participaram da formação intitulada Trabalho Colaborativo em Rede no Projeto UCA, oferecida pela pesquisadora.

A opção por uma instituição contemplada com o Projeto UCA ocorreu em razão dos seguintes aspectos: utilização intensiva do laptop educacional nas atividades pedagógicas; acesso à Internet, fundamental para o trabalho em rede; crença nos aspectos relativos à conectividade, à mobilidade e ao modelo 1:1 como elementos que favorecem as práticas de aprendizagem colaborativa em rede; aquiescência da Escola e disponibilidade dos professores em colaborar com a pesquisa.

O questionário foi o instrumento de coleta de dados utilizado para sondar os conhecimentos prévios dos educadores sobre trabalho colaborativo em rede, bem como suas expectativas em relação à formação que seria oferecida. A nomenclatura dada aos educadores foi P1 a P23, atribuída aleatoriamente.

Após a adesão dos professores, a pesquisadora criou um curso no ambiente Sócrates [http://www.vdl.ufc.br/socrates], intitulado Trabalho Colaborativo em Rede no Projeto UCA com o intuito de ser um processo formativo sobre aprendizagem colaborativa em rede. O curso teve duração de $40 \mathrm{~h} / \mathrm{a}$ na modalidade semipresencial, foi planejado para ter duração de três meses e composto por cinco aulas. As atividades mesclaram atividades individuais e em grupo, procurando aliar teoria e prática, como indicavam as expectativas e necessidades dos professores.

As ferramentas próprias do curso utilizadas no ambiente virtual foram as seguintes: aulas para inserção dos planos de aula; cronograma onde foram inseridos os prazos para o cumprimento das atividades; fórum para discussão dos temas propostos; material de referência onde foram postados o programa do curso e os textos para estudo; portfólio para postagem de atividades individuais e em grupo; acompanhamento para que a pesquisadora pudesse acompanhar o desempenho dos docentes; mensagem para a comunicação entre a pesquisadora e os professores.

As sessões reflexivas constituíram momentos de reflexão e discussão sobre os conteúdos em estudo, dúvidas e dificuldades em relação à formação. A pesquisadora 
V Congresso Brasileiro de Informática na Educação (CBIE 2016)

Anais do XXII Workshop de Informática na Escola (WIE 2016)

acompanhava os professores em seus horários de planejamento e os auxiliava na compreensão dos textos, no uso do ambiente Sócrates e na realização das atividades.

\section{Resultados e discussão}

As expectativas para a formação oferecida sobre trabalho colaborativo com suporte computacional foram coletadas no questionário aplicado aos professores e no fórum de apresentação do curso intitulado Trabalho Colaborativo em Rede no Projeto UCA, realizado no ambiente virtual colaborativo Sócrates. Em linhas gerais, eles desejavam aprimorar seus conhecimentos, conhecer e experimentar novas metodologias, aliar teoria e prática, bem como aperfeiçoar suas aulas com o suporte do laptop. Os dados apresentados a seguir foram coletados nos questionários respondidos pelos professores e nos fóruns do curso.

Os professores foram unânimes na intenção de participar do curso com empenho e aprimorar seus conhecimentos. O P1 gosta de estudar, de enfrentar desafios e deseja ingressar no mestrado em Educação. Afirmou ele: "participar desse curso é uma oportunidade de aprender mais e poder aperfeiçoar mais minha prática pedagógica". O P2, mesmo com vinte anos de profissão, também está aberto a novas aprendizagens e demonstrou uma postura colaborativa: "Gosto muito de desafios e procuro fazer de tudo para melhor ajudar no que for possível". O P3, como os outros dois, mostrou-se disposto a aprender: "Estou confiante de alcançar meus objetivos e aprimorar meus conhecimentos na área da Informática". O P22 demonstrou interesse pelo trabalho colaborativo como metodologia promotora de aprendizagem: "As expectativas quanto ao curso são as melhores possíveis, pois o trabalho colaborativo só vem ajudar a aprendizagem dos alunos".

Outros docentes detiveram-se mais no uso das ferramentas tecnológicas. O P18 pretendia utilizar as TDIC em sua vida pessoal e profissional: "Acredito que este curso irá abrir novas janelas para que eu possa usar com mais eficácia as novas tecnologias no meu dia a dia profissional e pessoal". O P4 preocupou-se em levar os conhecimentos adquiridos no curso para sua prática pedagógica: "Pretendo [...] desenvolver algumas habilidades junto ao ambiente informatizado, tendo assim a nossa disposição mais uma ferramenta que nos possibilita aulas dinâmicas e interativas".

As necessidades e os anseios dos professores expressam bem o pensamento de Almeida e Prado (2011, p. 39) ao se referirem à importância da formação docente no processo de integração do laptop às práticas pedagógicas. As autoras reforçam a importância da oferta de programas de formação docente com com ênfase "nas práticas escolares baseadas no uso do laptop educacional, na reflexão sobre as mesmas, na identificação e análise das mudanças ocorridas, das dificuldades enfrentadas e das decisões necessárias para que essas práticas possam se concretizar".

Quando indagados se já haviam lido ou estudado algo sobre aprendizagem colaborativa, apenas 5 (cinco) professores informaram que já tinham entrado em contato com essa temática e, acerca da aprendizagem colaborativa em rede, somente 9 (nove) educadores responderam afirmativamente. Mesmo assim, todos achavam possível aprender com outras pessoas através da Internet, gostariam de ler/estudar sobre aprendizagem colaborativa em rede e acreditavam que esse estudo poderia ajudar no 
V Congresso Brasileiro de Informática na Educação (CBIE 2016)

Anais do XXII Workshop de Informática na Escola (WIE 2016)

aperfeiçoamento da sua prática docente em relação a trabalho em grupo usando o laptop educacional e a Internet com seus alunos.

Os professores desejavam conhecer ferramentas que favorecessem a aprendizagem colaborativa e os auxiliassem a incrementar suas aulas, o que pôde ser percebido nas respostas dos docentes P3 e P6. O educador P3 demonstrou interesse em ver "dicas de sites e como posso utilizá-los e como funciona a aprendizagem colaborativa". O P6 "gostaria de saber como usar com mais eficiência as ferramentas que nos possibilitam a aprendizagem colaborativa".

Como se tratava de uma escola UCA, a preocupação com a prática foi reforçada pelos docentes $\mathrm{P} 7$ e P9. O educador P7 informou que "gostaria de tornar-me conhecedor de uma definição bem exemplificada para 'aprendizagem colaborativa em rede', para que minhas aulas tivessem mais qualidade quando o UCA [laptop] fosse levado à sala". O P9 esperava aprender "como dar uma aula bem produtiva usando o trabalho em rede (internet)".

Para que os professores compreendessem o significado do termo colaboração, foi proposta a leitura de um texto elaborado pela pesquisadora e intitulado Colaboração ou Cooperação?, postado no Material de Referência do ambiente Sócrates, com o intuito inicial de promover a reflexão sobre o uso desses termos, bem como fomentar a discussão sobre o sentido da colaboração que se pretendia suscitar entre os docentes.

Os professores focaram na ajuda mútua e na participação de todos para a realização das atividades. O P2 explicou que "a ajuda mútua é uma grande ferramenta para se alcançar objetivos, pois cada um colocando sua peça no quebra-cabeças poderemos chegar a um perfeito produto final". A participação de todos foi observada pelo P1: "A colaboração acontece quando todos participam de uma determinada atividade. [...] Fica impossível perceber o quanto cada um contribuiu".

A comunicação e a interação entre docentes e discentes para que a aprendizagem colaborativa aconteça foi enfatizada pelo professor P10: “O fundamento para que se compreenda a aprendizagem colaborativa é a participação do docente e a colaboração do discente. Esse processo acontece quando todos os alunos da comunidade participam da criação e manutenção da comunicação".

Os professores P1, P2 e P10 estão alinhados com o pensamento de Fiorentini (2006). Este autor faz referência a relações não-hierárquicas, em que a liderança e a corresponsabilidade são compartilhadas entre os membros de um grupo colaborativo, que inclui, naturalmente, professores e alunos em processo de aprendizagem.

Os professores P5 e P16 apresentaram posicionamento semelhante acerca da divisão de tarefas no trabalho colaborativo. O P5 informou que, "na colaboração, todos trabalham conjuntamente em todas as etapas de um trabalho com um fim em comum". O P16 reforçou essa ideia quando afirmou que "não existe um trabalho individual, todos realizam cada etapa de um trabalho em conjunto, não havendo separação em hipótese alguma". Tais ideias encontram amparo nos aspectos elencados por Stahl, Koschmann e Suthers (2006).

Para o estudo sobre os benefícios do trabalho colaborativo, a pesquisadora propôs a leitura do texto Entendendo o Trabalho Colaborativo em Educação e Revelando seus Benefícios (Damiani, 2008), que postou no Material de Referência e a 
V Congresso Brasileiro de Informática na Educação (CBIE 2016)

Anais do XXII Workshop de Informática na Escola (WIE 2016)

discussão no fórum 2, sobre o significado do trabalho colaborativo e seus benefícios para professores e alunos.

O P2 informou que se tratava de uma proposta "em que se trabalha muito com compartilhamento de ideias para chegar a um objetivo comum. Há muitos benefícios que fazem com que haja uma aprendizagem mútua". O P1 ressaltou que "trabalho colaborativo é uma forma de envolver todos os alunos numa determinada atividade, levando-se em consideração os saberes de cada um e proporcionando a troca de conhecimentos".

Acerca das interações naturais que ocorrem entre os alunos e dos processos de aprendizagem individual e coletiva, Aparici e Acedo (2010, p. 138) ressaltam que o ser humano tem essa tendência natural à vida social e, nesse processo, realiza seu desenvolvimento pessoal e profissional em interação com seus pares. Para eles, "a aprendizagem tem uma dimensão individual de análise e conceituação que se desenvolve corretamente em colaboração com outros indivíduos".

Sobre o significado do trabalho colaborativo, o P11 entendeu que se traduz por "aprendizagem, desenvolvimento, benefícios e engajamento ativo", no que obteve apoio do P7, o qual reiterou que "um trabalho colaborativo é um trabalho em que todos os envolvidos compartilham as decisões tomadas e são responsáveis pela qualidade do que é produzido em conjunto, conforme suas possibilidades e interesses".

O P10 posicionou-se favoravelmente quanto ao parecer das colegas e fez um paralelo entre as práticas tradicionais e o trabalho colaborativo, enfatizando a mudança de postura do educador e a necessária interação entre professor e alunos para a produção da aprendizagem. Ele asseverou que "o trabalho colaborativo é a junção do docente que, ao invés de só dar o conteúdo, ele colabora para que os dois, discente e docente, possam aprender juntos e trabalhem para o bem comum, que é o aprendizado de todos".

Sobre essa parceria entre docentes e discentes, o P23 lembrou que essa proposta "significa um trabalho desenvolvido em parceria, em equipe, de forma coletiva, compartilhando os conhecimentos". Essa forma de pensar alinha-se com o pensamento de Aparici e Acedo (2010, p. 139), quando afirmam que o trabalho colaborativo é "um ensino de caráter horizontal para realizar um processo de aprendizagem colaborativa".

Quanto aos benefícios do trabalho colaborativo para os professores, o P11 salientou que concorre para o "enriquecimento da maneira de pensar, agir e resolver problemas, criando possibilidades de sucesso à difícil tarefa pedagógica". Nessa mesma linha de pensamento, o P4 informou que favorece o trabalho com "a resolução de problemas". Para o P23, "além de trabalhar a socialização, melhora o desempenho, [o professor] ganha mais experiência. E assim, com essa troca de conhecimentos os mantém mais capazes, eficientes e dinâmicos".

Para que os professores se apropriassem dos fundamentos do trabalho colaborativo com suporte computacional, a pesquisadora propôs o estudo do texto Aprendizagem Colaborativa com Suporte Computacional [Stahl; Koschmann e Suthers 2006], postado no Material de Referência do Sócrates. A pesquisadora solicitou que os professores se distribuíssem em cinco grupos, conforme os critérios de afinidade e facilidade de realização da atividade.

O trabalho consistia no estudo em grupo e na confecção do resumo do texto usando a ferramenta de texto colaborativo do Google Drive. Para isso, a pesquisadora 
criou o documento e compartilhou com os professores. Os grupos discutiriam o texto inteiro e escolheriam um dos tópicos para desenvolver com mais profundidade, além de contribuir para enriquecer o trabalho como um todo. Poderiam colocar imagens, links, relatos de experiências e outras contribuições que pudessem enriquecer o trabalho.

Após a realização dessa atividade, teria início a aula 4, na qual os professores deveriam pesquisar, ainda com os mesmos grupos da atividade anterior, experiências de trabalho colaborativo com suporte computacional e socializar, em slides produzidos no Google Drive, ferramenta Apresentação, previamente criada pela pesquisadora e compartilhada com os docentes.

Realizadas essas duas fases, os professores passariam ao fórum 3 para socializar a experiência de produzir colaborativamente um texto e uma apresentação de slides com os colegas, discutir o papel da tecnologia nesse processo e se eles julgavam que tinha havido aprendizagem nessa forma de trabalhar os conteúdos.

Nas duas atividades, os docentes tiveram muitas dificuldades em razão de dois motivos principais: a) falta de tempo de se dedicarem à tarefa devido à finalização do ano letivo, ao acúmulo de atividades relativas à correção de trabalhos, ao lançamento de notas e à preparação da recuperação final; b) dificuldades em utilizar as ferramentas de texto e apresentação de slides do Google Drive. Para efeito de uso das ferramentas colaborativas online, os objetivos foram cumpridos, mas do ponto de vista do trabalho colaborativo, esse resultado não surtiu o efeito esperado, uma vez que os grupos não tiveram a visão geral do trabalho produzido.

A aula 5 previa o planejamento de atividades colaborativas com suporte do laptop, utilizando os mesmos grupos das aulas 3 e 4. Como os professores estavam muito envolvidos com a finalização do ano letivo, somente uma equipe conseguiu realizar essa atividade e socializou com os colegas.

A despeito dessas dificuldades com a finalização do curso, houve boa participação no fórum 3, criado para a socialização das experiências de produção colaborativa das atividades. O P2 destacou a ajuda mútua para a realização das atividades e o suporte computacional como apoio à pesquisa. Disse ele: "Com certeza foi uma experiência muito gratificante, pois cada um procurou uma maneira de ajudar na construção do texto. Vejo que o computador é um recurso de suma importância no processo, ajudando muito como fonte de pesquisa".

Os professores P23 e P7 também consideraram importante a oportunidade de debater ideias e opiniões, além da vantagem de usar o laptop como recurso que torna mais concreto o ato de aprender. O P23 destacou a forma de produção de textos e slides em grupo, colaborativamente". O P7 chamou a atenção para o fato de que "realizar uma atividade em grupo proporciona momentos de discussões de ideias onde várias opiniões podem ser sugeridas ajudando na solução de problemas".

Diante disso, confirma-se a importância dos instrumentos como mediadores que favorecem a aprendizagem. No caso específico dos recursos tecnológicos, três formas de mediação no uso do computador e da Internet foram percebidas na realização dessa atividade, como preconiza Freitas (2008): mediação exercida pelo computador como ferramenta material; mediação através do uso das diversas linguagens; mediação entre os interlocutores. 
V Congresso Brasileiro de Informática na Educação (CBIE 2016)

Anais do XXII Workshop de Informática na Escola (WIE 2016)

\section{Conclusões}

Os resultados obtidos permitem concluir que os professores demonstraram empenho nas atividades propostas durante a formação oferecida pela pesquisadora e interesse em usar os conhecimentos construídos em sua prática pedagógica.

As ferramentas digitais utilizadas foram reconhecidas como recurso pedagógico e bem aproveitadas durante a formação, visto que houve aprendizagem de recursos tecnológicos online, ferramentas colaborativas que podem ser usadas pelos professores em qualquer tempo e espaço, bem como alguns aplicativos do laptop.

A despeito de a formação ter sido realizada na própria escola, em serviço e com anuência de todos os docentes, ainda faltou tempo para que os professores estudassem juntos e discutissem os textos e atividades presencialmente. $O$ suporte virtual complementou essa limitação e ofereceu as ferramentas necessárias para o trabalho colaborativo online. O ambiente Sócrates ofereceu o suporte para a discussão de ideias, a postagem de materiais, a organização e o registro das atividades com a segurança necessária ao trabalho escolar.

As ferramentas do Google Drive favoreceram a produção coletiva e colaborativa, posto que tais recursos têm essa função como foco. Ao lado dos aplicativos do laptop, foi possível vencer as dificuldades de acesso à Internet, ainda presentes e constantes na Escola PAS. De todo modo, houve trabalho colaborativo com uso de ferramentas propriamente colaborativas, como as do Google Drive, e ocasiões em que professores trabalharam colaborativamente, mesmo utilizando recursos que não tinham essa finalidade primordial.

\section{Referências}

Abegg, I., Bastos, F. P. e Müller, F. M. (2010) "Ensino-aprendizagem colaborativo mediado pelo wiki do Moodle", In: Educar em Revista, Curitiba, Brasil, n. 38, p. 205-218, set./dez. Disponível em: http://ojs.c3sl.ufpr.br/ojs2/index.php/educar/article/viewFile/13129/13530. Acesso em 10 jan. 2012.

Almeida, M. E. B.; Prado, M. E. B. B. (2003) "Criando situações de aprendizagem colaborativa". In: IX Workshop de Informática na Escola, pp. 53-60. Disponível em: http://br-ie.org/pub/index.php/wie/article/view/774/760. Acesso em 09 jan. 2012.

(2011) Indicadores para a formação de educadores para a integração do laptop na escola. In: Almeida, M. E. B.; Prado, M. E. B. B. (Org.) "O computador portátil na escola: mudanças e desafios nos processos de ensino e aprendizagem". São Paulo: Avercamp.

Aparici, R. e Acedo, S. O. (2010) "Aprendizagem colaborativa e ensino virtual: uma experiência no dia-a-dia de uma universidade a distância", In: Silva, Marco; Pesce, Lucila e Zuin, Antônio. Educação online: cenário, formação e questões didáticometodológicas. Rio de Janeiro: Wac Editora.

Damiani, Magda Floriana. (2008) "Entendendo o trabalho colaborativo em educação e revelando seus benefícios". Educar, Curitiba, Editora UFPR, n. 31, p. 213-230. 
V Congresso Brasileiro de Informática na Educação (CBIE 2016)

Anais do XXII Workshop de Informática na Escola (WIE 2016)

Fiorentini, Dario. (2006) Pesquisar práticas colaborativas ou pesquisar colaborativamente? In: Borba, Marcelo de Carvalho; Araújo, Jussara de Loiola (Orgs). "Pesquisa qualitativa em educação matemática". Belo Horizonte- MG: Autêntica, 2ed.

Freitas, Maria Teresa de Assunção. (2008) "Computador/internet como instrumentos de aprendizagem: uma reflexão a partir da abordagem Psicológica Histórico-Cultural". In: $2^{\circ}$ Simpósio Hipertexto e Tecnologias na Educação, Universidade Federal de Pernambuco.

Le Boterf, G. (1984) "Pesquisa Participante: propostas e reflexões metodológicas". In: Brandão, C. R. (Org.). Repensando a pesquisa participante. São Paulo: Ed. Brasiliense.

Lima, T. C. B. (2008) "Ação educativa e tecnologias digitais: análise sobre os saberes colaborativos". Tese de Doutorado. Fortaleza: Universidade Federal do Ceará.

Lipponen, L. (2002) "Exploring foundations for computer supported collaborative learning". Department of Psychology, University of Helsinki, Finland. Proceedings of CSCL, page 72. Acesso em 18 nov. 2011.

Lipponen, L., Hakkarainen, K. e Paavola, S. (2004). "Practices and Orientations of Computer Supported Collaborative Learning”. In: J. Strijbos, P. Kirschner \& R. Martens (eds.). What we know about CSCL, and implementing it in higher education (pp. 31-50). Boston, MA: Kluwer Academic Publishers. In: https://www.academia.edu/350359/Lipponen_L._Hakkarainen_K._and_Paavola_S._ 2004_Practices_and_orientations_of_CSCL Acesso em 28jul14.

Luckin, Rosemary et al. (2005) "Using mobile technology to create flexible learning contexts". Journal of Interactive Media in Education, (22). Disponível em http://jime.open.ac.uk/article/2005-22/299 Acesso em: 20 fev. 2012.

Roschelle, J.; Teasley, S. (1995). The construction of shared knowledge in collaborative problem solving. In: O’Malley, C. E., (ed.), "Computer supported collaborative learning". Pp. 69-97. Springer-Verlag, Heildelberg.

Silva, M. A., Barbosa, Jaiane Ramos e Castro-Filho, José Aires de. (2013) Aprendendo e ensinando colaborativamente com o suporte do laptop educacional. In: Anais do II Congresso Brasileiro de Informática na Educação 2013 - III Workshop sobre Formação e Experiências Educacionais no Programa Um Computador por Aluno. Campinas-SP, pp. 630-639.

Silva, M. A., Barbosa, Jaiane Ramos e Castro-Filho, José Aires de. (2015) Trabalho Colaborativo: aprendendo e ensinando com o laptop. In: CASTRO-FILHO, José Aires de; SILVA, Maria Auricélia da; MAIA, Dennys Leite (Orgs). Lições do Projeto Um Computador por Aluno: estudos e pesquisas no contexto da escola pública. Fortaleza: EdUECE.

Stahl, G., Koschmann, T. e Suthers, D. (2006). "Computer-supported collaborative learning: an historical perspective". In: R. K. Sawyer (Ed.), Cambridge handbook of the learning sciences (pp. 409-426). Cambridge, UK: Cambridge University Press. Disponível em: http://gerrystahl.net/cscl/CSCL_Portuguese.pdf in Portuguese. Acesso em 12 dez. 2011. 